\title{
Factor VIla and Factor IXa Inhibitors as Anticoagulants: A Review
}

\author{
Kumbhar Santosh Sahadeo, Choudhari Prafulla Balkrishna, Pawar Vasanti Suresh, Bhatia Neela \\ Manish, Bhatia Manish Sudesh
}

Drug Design and Development Group, Department of Pharmaceutical Chemistry, Bharati Vidyapeeth College of Pharmacy, Kolhapur (MH), INDIA.

\begin{abstract}
Introduction: Anticoagulants are used as preventive agents in deep vein thrombosis to prevent blood clots, venous and arterial thromboembolism, but the current therapy of anticoagulants have several limitations like patient variable response, enhanced chances of bleeding and heparin-induced thrombocytopenia (HIT). Factor VIla and factor IXa play an important role in coagulation cascade and hence are promising targets for drug development. FIXa has been targeted by various means including oral inhibitors (TTP889), monoclonal antibodies (SB249417) and RNA aptamers which have passed various phases of clinical trials. Objectives: Though advances in development of inhibitors of FVIIa/TF and FIXa have reached various phases of clinical trials none of the clinical trial candidates have reached the market. Methodology: This review summarizes available information on FVIIa/TF and FIXa, their active site, crystallographic structure, available inhibitors, earlyphase clinical trial study and also the recent efforts in the discovery of FVIIa/TF and FIXa inhibitors. Summary: Despite the fact that more complexity is observed in designing of anticoagulant as FVIla/TF complex and FIXa inhibitors, these will remain an important and validated target for the design and development of anticoagulants.
\end{abstract}

Key words: Anticoagulants, FVIIa/TF, FIXa, Inhibitors, Serine protease.

\section{INTRODUCTION}

\section{Coagulation Cascade}

Our human body is designed to maintain a complex network of vasculature that is capable of continuously circulating blood for decades. It is also responsible for its own repair when internal or external forces disturb the integrity of this system. Blood coagulation means conversion of fluid blood to a solid clot or gel like structure. The conversion of soluble fibrinogen to insoluble fibrin is the main event in the blood coagulation cascade. ${ }^{1}$ It is composed of two separate pathways known as the extrinsic or tissue factor pathway (because some components come from outside the blood) and the intrinsic or contact factor pathway (because all the components are present in blood). ${ }^{2}$ Extrinsic pathway is mainly important in controlling blood coagulation. ${ }^{1}$ The extrinsic pathway is initiated when factor VIIa (FVIIa) and tissue factor (TF) comes together. TF is the most important originator of coagulation. ${ }^{3}$ The initiation of extrinsic pathway is triggered by activation of TF which is the cellular receptor for factor VII which undergoes an active site modification in the presence of $\mathrm{Ca}^{2+}$. This results in the quick activation of factor VII to VIIa. Even though segregated from TF, FVIIa is always present in the circulating blood at low basal levels. When TF is exposed to the blood, it forms a complex with circulating free FVIIa which will lead to a formation of TF/FVIIa complex, which can be considered as the beginning of thrombin generation ${ }^{4}$. During the amplification phase, thrombin continues to activate platelets ${ }^{5}$ as well as FVIII, FV and FXI. At the beginning of the intrinsic
Submission Date: 25-08-2016; Revision Date: 26-09-2016; Accepted Date: 27-09-2016

DOI: 10.5530/ijper.51.1.1 Correspondence: Mr. S. S. Kumbhar, Bharati Vidyapeeth College of Pharmacy,

Near Chitranagari, Kolhapur, (MH), INDIA.

Phone no: +912312637286 $+91-9860134040$

E-mail: santosh.kumbhar0307 @gmail.com

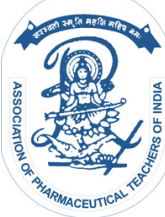

www.ijper.org 
pathway, factor XIIa will activate FXI to FXIa. The coagulation FIX is activated by FXIa which leads to the formation of intrinsic complex which is composed of FIXa, FVIIIa, $\mathrm{Ca}^{2+}$ and anionic phospholipids. This further leads to an activation of FX and its subsequent formation of prothrombinase complex. This complex of prothrombinase produces thrombin over 1,00,000 times faster than free FXa. ${ }^{6}$

\section{Anticoagulants}

Anticoagulants are the class of drugs that works to prevent blood coagulation, which is used for coagulation disorders and also as prophylactic in patients with mechanical heart valves as a lifelong therapy. ${ }^{7}$ Blood Clotting is the complex process guided by bimolecular proteins, known as clotting factors. In past decade these clotting factors have emerged as potential targets for anticoagulant molecules. ${ }^{8}$ Parenteral anticoagulants like synthetic analogues of heparin and low-molecularweight heparin are in clinical use. Fondaparinux was the first synthetic highly specific pentasaccharide used in treatment of venous thromboembolism (VTE). Idraparinux, a long-acting pentasaccharide administered subcutaneously, which is also used in the treatment of VTE and for prophylaxis of cardio embolic events in patients having atrial fibrillation. ${ }^{9}$ Common anticoagulants, like warfarin or heparin and its derivatives are indirect inhibitors which act as vitamin $\mathrm{K}$ antagonist or antithrombin, respectively. Warfarin is the only orally active anticoagulant which is clinically used now-a-days. Coumarin derivatives like warfarin has been the drug of choice for the prevention and treatment of arterial and venous thrombotic disorders for more than 40 years. Treatment with Warfarin becomes precarious as it has a lower therapeutic window requires critical dose monitoring. ${ }^{10}$ Rivaroxaban and Apixaban have been approved for treatment of venous thromboembolism (VTE), prevention after elective hip or knee replacement in adults, stroke prevention and systemic embolization in non-valvular atrial fibrillation. ${ }^{11,12}$ Ximelagatran was the first oral direct thrombin inhibitor and had confirmed efficacy for prevention and treatment of VTE, stroke prevention and recurrent coronary events after acute myocardial infarction. But it was withdrawn by AstraZeneca in the year 2006 because of liver toxicity. ${ }^{13,14}$ Currently available anticoagulant therapy suffer from some limitations including inability to act on the clot bound thrombin, variable patient responses, heparininduced thrombocytopenia (HIT) and the enhanced chance of bleeding. ${ }^{15,16}$

\section{FVIla and FIXa Inhibitors as Anticoagulants}

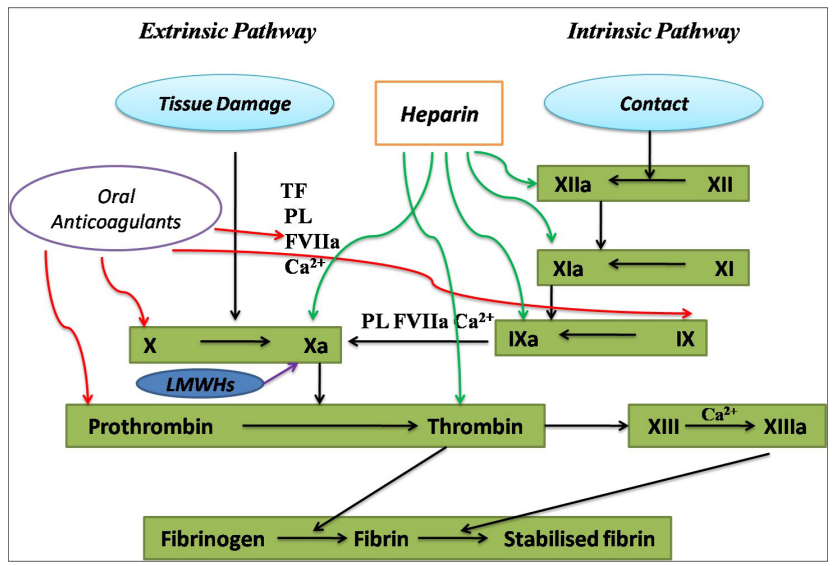

Figure 1: Coagulation cascade and sites of action of anticoagulants (Oral anticoagulants, Heparin, low-molecular weight heparins LMWHs). Figure showing the coagulation process and general anticoagulants used at each stage in both extrinsic and intrinsic pathway.

FVIIa and FIXa inhibitors are the different class of anticoagulant agents. FVIIa and FIXa are the important targets in coagulation cascade due to their strategic presence at the junction of both extrinsic and intrinsic pathways. These agents may further act as selective and potent antithrombotic. Coagulation cascade and sites of action of anticoagulant drugs are shown in Figure 1. Development of anticoagulant strategies are based on agents that are particularly used either as therapeutic or prophylactic agents. The initiation of coagulation process can be inhibited by agents that target FVIIa and TF complex, while generation of thrombin can be blocked by the drugs that target FIXa, Xa, FVa and FVIIIa, whereas thrombin inhibitors are used to prevent the formation of fibrin.'

\section{ACTIVE SITE CARACTERIZATION}

\section{FVIla active site}

In the development of orally active small molecules, success in preclinical models and clinical trials of FVIIa/ TF inhibitors was an important achievement. ${ }^{17} \mathrm{FVII}$ is an enzyme of the serine protease class, formerly known as proconvertin. The X-ray crystallographic structure of FVIIa/TF complex was first published in 1996 by Banner et al. ${ }^{18} \mathrm{FVII}$ is a serine protease class of enzyme which consists of 3 pockets S1, S2, S3. There are some differences in the active site of the three pockets and these differences can prove handy in development of specific ligands for these pockets. The S1 pocket of all the serine protease family have the same catalytic harmony SER195-HIS57-ASP102, also having high degree of homology in their amino acid sequence and spatial arrangement in the protease domain and active 


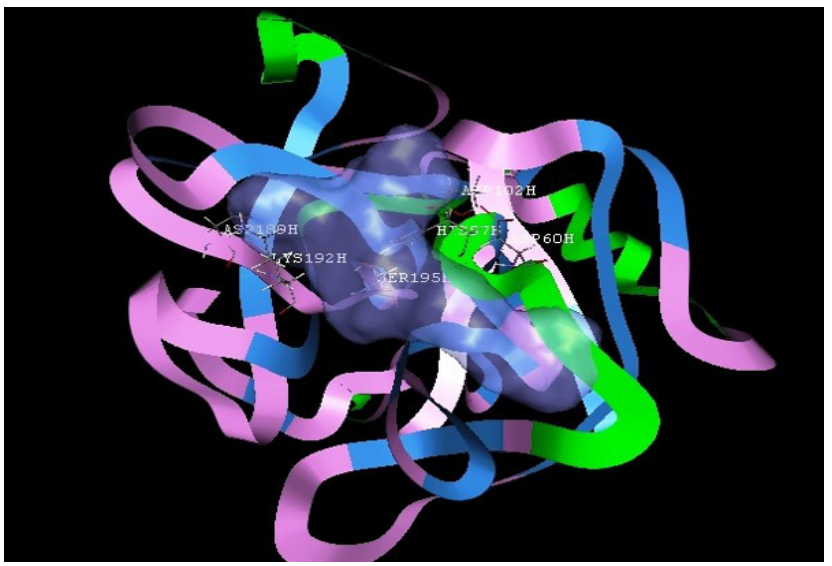

Figure 2: Ribbon structure of FVIla and active site residues of pocket S1 created using Vlife MDS 4.3 PDB ID (1CVW). Figure showing active site amino acids which are responsible for inhibition of FVIla leads to coagulation.

site. The characteristic feature of this serine protease has a deep S1 pocket with ASP189 acidic amino acid at the bottom i. e. the catalytic domain of S1 pocket, which forms salt bridge with basic ARG or LYS. ${ }^{19,20}$ Whereas, S2 shows the TRP215 in the beta-sheet region and HIS57 in the S3 pocket at beta-sheet region. ${ }^{16}$ Majority of the FVIIa inhibitors reported till date have a benzamidine or amidine P1 moiety. SER190 in S1 pocket is an important for FVIIa. Some of the FVIIa inhibitors shown H-bond interactions with SER190 which shows significant interaction for anticoagulant activity. ${ }^{21,22}$ The ribbon structure of FVIIa and active site residues after minimization of energy (MMFF force field used) is shown in Figure 2. ${ }^{23-25}$

\section{FIXa active site}

FIX is also known as Christmas factor which is a serine protease family enzyme of coagulation cascade. Deficiency of FIX leads to hemophilia B. FIX was discovered in 1952 when a young boy named Stephen Christmas who lacks this factor which led to haemophilia. ${ }^{26}$ FIX is synthesized in liver which plays an important role in the blood coagulation and share a common domain ${ }^{18}$. $\mathrm{N}$-terminal GLA domain contain $12 \gamma$-carboxy glutamic acid residues. Epidermal growth factor (EGF)like domains of $\mathrm{N}$-terminal are responsible for binding with TF. ${ }^{27,28}$ Distraction in the EGF domains indicates reduced binding of FVIIa/TF and FVIIIa ${ }^{29}$ Figure 3. FIXa mainly comes under the intrinsic pathway of blood coagulation which further leads to activation of FX therefore FIXa is the main target for development of novel anticoagulants. ${ }^{30,31}$ The activity of FIX is regulated by various factors like anti-thrombin III, nexin-2/ amyloid $\alpha$-protein precursor, protein Z-dependent protease inhibitor and neutrophil elastase. ${ }^{32-34}$ The serine

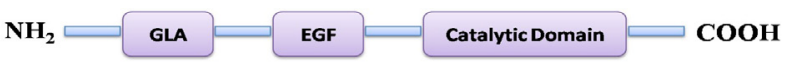

Figure 3: FIX structure-function domains: Amino-GLA domain, EGF-like domain etc. Figure showing the (EGF) and catalytic like domains of $\mathrm{N}$-terminal which are liable for binding with TF.

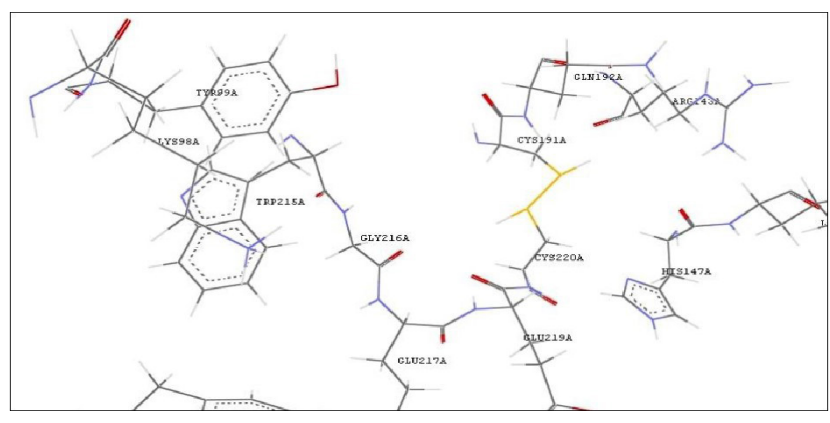

Figure 4: Active site amino acids of FIXa binding pocket S1 (PDB ID 3LC5). LYS98 and ARG143 in pocket S1 are essential for FIXa inhibition. Shape of pocket $\mathrm{S} 1$ is like $\mathrm{U}$ or V shape.

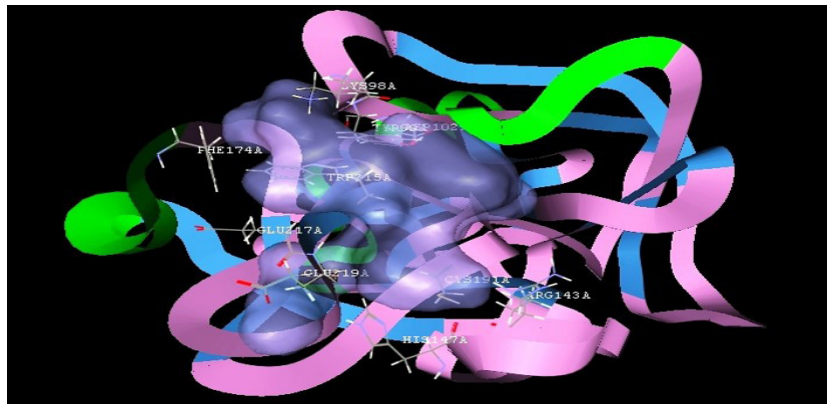

Figure 5: Ribbon structure of FIXa and active site residues pocket S1 PDB ID (3LC5). Active site amino acids responsible for FIXa inhibition.

protease domain of FIX is required for blood coagulation which act as a catalytic amino acid. Serine protease contain SER, HIS, and ASP which forms cleavage at ARG and VAL to form a salt bridge with ASP. The shape and size of second pocket of FIXa is similar to trypsin, FXa and thrombin. LYS98 and ARG143 in pocket $\mathrm{S} 1$ are essential for FIXa inhibition, active site amino acids of FIXa binding pocket S1 (PDB ID 3LC5) Figure 4. TYR99 in FIXa is able to produce different types of conformations that depends on which type of ligand binds with the active site. Normally TYR99 is observed to block pocket $2^{\text {nd }}$ and $4^{\text {th }}$ pocket. ${ }^{35}$ The ribbon structure of FIXa and active site residues after energy minimization (MMFF force field used) is shown in Figure 5. ${ }^{23-25}$

\section{FVIIa INHIBITORS}

There are number of FVIIa/TF inhibitors which are reported and some of them shows in-vivo efficacy after IV administration, but the main challenge remains into 
the invention of an oral bioavailability of drug. Oral bioavailability of drug is successful only when there is a significant achievement between the inhibitor characteristics and their pharmacokinetic properties.

\section{2-Aryl substituted 4H-3, 1-Benzoxazin-4ones}

They act by selective acylation of the FVIIa SER195 by benzoxazinone lactone. ${ }^{36} \mathrm{IC}_{50}$ of FVIIa/TF complex inhibition is $0.82 \mu \mathrm{M}$ while for $\mathrm{FXa}$ is $112 \mu \mathrm{M}$. Main two factors that affect inhibitory activity are electronegative groups present on 2-aryl ring and benzoxazinone ring at positions $5,6,7$, and 8 .<smiles>O=c1oc(-c2c(F)cccc2F)nc2cc([N+](=O)[O-])ccc12</smiles>

\section{5-azaindole derivatives}

Incorporation of an alkyl moiety on the initial urea lead will increase in potency and selectivity of the compound. The amidine containing analog shows good potency for FVIIa versus the FXa. Reported $\mathrm{Ki}=0.013$ $\mu \mathrm{M}$ and more than 200 fold selectivity with FVIIa. ${ }^{37}$<smiles>N=C(N)c1ccc2[nH]c(-c3cccc(-c4cc(CNC(N)=O)ccc4O)c3O)nc2c1</smiles>

\section{5-amidino-2-(2-hydroxy-biphenyl-3-yl)-} benzimidazole derivatives

Incorporation of 2-hydroxy on the terminal aryl ring shows significant increase in potency and selectivity towards FVIIa. Hydrogen bond interaction between a hydroxyl group on distal ring of the biaryl system and LYS192 will increase selectivity and potency for FVIIa. Having $\mathrm{Ki}=0.074 \mu \mathrm{M} .^{38}$<smiles>[R]c1cc(C(CC(=O)O)C(=O)O)cc(-c2nc3cc(C(=N)N)ccc3[nH]2)c1O</smiles>

2-[5-(5-carbamimidoyl-1H-benzoimidazol-2-yl)-50fluoro-6,20dihydroxy-biphenyl-3-yl] succinic acid scaffold

Selective and potent FVIIa/TF inhibitors were generated through structure based drug design and pharmacokinetic properties were evaluated by baboon thrombosis model. Allometric scaling predict that it could be appropriate for human. FVIIa/TF inhibitory analog were developed by exploring the para position on the C-ring phenol with the urea by one methylene unit. $\mathrm{Ki}=0.002 \mu \mathrm{M} .{ }^{39}$<smiles>[R]c1ccc(O)c(-c2cc(C(CC(=O)O)C(=O)O)cc(-c3nc4cc(C(=N)N)ccc4[nH]3)c2O)c1</smiles>

\section{Pyridinone based inhibitor}

By replacing nitrogen at position 4 of pyrazinone, pyridinone based inhibitors are produced. ${ }^{40}$ Developed compound have $\mathrm{IC}_{50}=84 \mathrm{nM}$ against FVIIa/TF.<smiles>CC(C)Nc1ccc(-c2cc(N)cc(N)c2)c(CC(=O)NCc2ccc(C(=N)N)cc2)[n+]1[O-]</smiles>

\section{4-amino-5-azaindole derivatives as inhibitors}

Substitution at the C5 position to enhance selectivity and potency are achieved on 5-amidino-benzimidazole analogs that contain acid moiety at $\mathrm{C} 5$ position of the central aryl ring having $\mathrm{Ki}=0.081 \mu \mathrm{M} .^{41}$

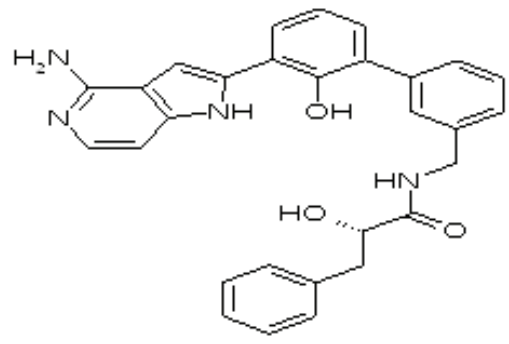

\section{FIXa INHIBITORS}


FIXa inhibitory strategies are emerging trends in drug design and development of drugs used as anticoagulant, because of promising results in the preclinical trials. FIX inhibitors displays an effective anticoagulation which will be helpful in reducing the risk of bleeding compared with unfractionated heparin. FIXa plays a key role in maintaining internal homeostasis in the intrinsic pathway of the coagulation.

\section{5-amidino-benzimidazole analogue}

In order to enhance potency towards FIXa and increase selectivity over the FVIIa and FXa, replacement of central phenol was done with the polar heterocycle like hydroxy pyrazole lead to promising results. Increases potency towards FIXa $\mathrm{Ki}=0.05 \mu \mathrm{M}$. Also increases selectivity and activity against FVIIa, FXa and APTT. ${ }^{42}$

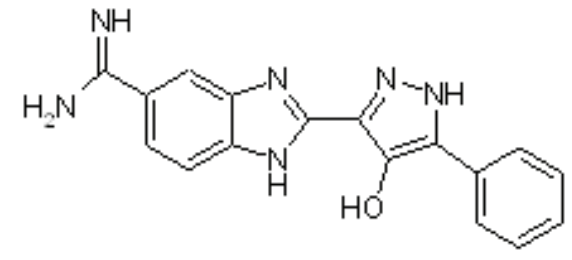

\section{Pyrazolo-pyridine and benzimidazole derivatives}

In order to develop FIXa inhibitors of pyrazolo-pyridine derivatives substitution with para-triazole significantly increases potency $\mathrm{Ki}=0.09 \mu \mathrm{M}$. whereas in benzimidazole derivatives potency is further improved by phenyl substitution $\mathrm{Ki}=0.016 \mu \mathrm{M}$. Further optimization needed to improve potency and selectivity towards the FIXa. ${ }^{43}$

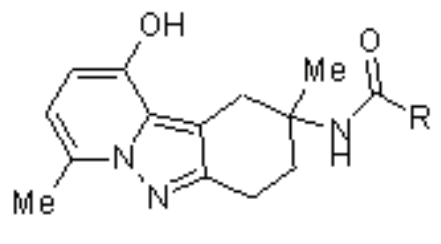

Pyrazolo-pyridine analog

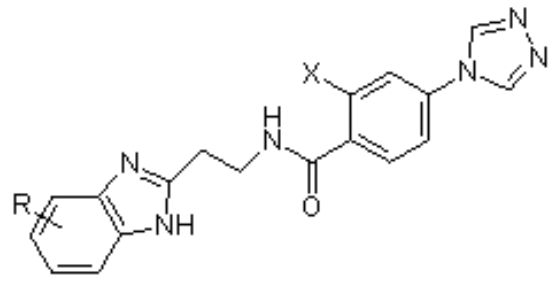

Benzimidazole analog

\section{2-amidino benzothiophene derivatives}

From the QSAR study of 2-amidinobenzothiophene derivatives of FIXa inhibitors, properties like steric, hydrophobic and $\mathrm{H}$-bond are taken in to consideration. Modifications at $2^{\text {nd }}$ position of the benzene ring and $6^{\text {th }}$ position of the benzothiophene will increase the activity against FIXa. $\mathrm{pIC}_{50}=8.70 \mathrm{nM}$; in particular electrostatic and hydrophilic substituent's at $2^{\text {nd }}$ position and hydrophobic group at $3^{\text {rd }}$ position of the phenyl ring increases activity and selectivity against FIXa. Also the pharmacophore study conclude that the aromatic features that are required for pi-stacking interaction with FIXa receptor which are contributed by benzothiophene and other to heterocyclic rings in the derivatives. The amidine group contributing the positive ionizable characteristic feature which is responsible for interaction with acidic amino acid like ASP. ${ }^{44-46}$

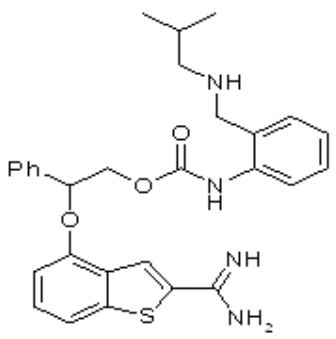

\section{Oral FIXa inhibitors}

TTP889 was the proprietary oral FIXa inhibitor manufactured by Transtech Pharma Winston Salem, North Carolina US. The inhibition was investigated by the FIXIT study. ${ }^{47}$ TTP889 show antithrombotic activity in rat and porcine arteriovenous shunt models. The FIXIT study was performed to determine the antithrombotic efficacy and safety of TTP889 in patients. A group of 261 patients undergoing hip fracture surgery was received TTP889 (300 mg daily) or placebo beginning 6-10 days after surgery, and standard prophylaxis for 5-9 days. Treatment was continued for three weeks followed by bilateral venography. The primary outcome was VTE which occurred in $32.1 \%$ of patients randomized to TTP889 and $28.2 \%$ of patients those receiving placebo. Major bleeding complications were not observed. The markers like thrombin generation and fibrin formation were checked after 14 and 28 days from the surgery and did not find much difference between TTP889 and placebo treated patients. Due to these results, development of TTP889 was halted. ${ }^{47,48}$

\section{RNA Aptamers}

These are oligonucleotides having ability to bind receptor with high affinity and selectivity. Pegnivacogin (RNA aptamer) is currently available FIXa inhibitor under development. It is the only drug developed with complementary antidote known as anivamersen. Pegnivacogin successfully completed Phase I and Phase II clinical trials and now phase III clinical trial have been started. Aptamers have the ability to bind to target with high affinity and selectivity. ${ }^{49}$ Pegnivacogin binds with FIXa 
selectively with high affinity as well as it also obstructs the activation of FXa by FVIIa/TF complex. Which leads to prolongation of the APT'T time..$^{50,51}$

\section{CURRENT STATUS OF FVIIa AND FIXa INHIBITORS}

Here we summarize the current status of development of FVIIa and FIXa inhibitors as an emerging class of novel anticoagulant drug like candidate. Though number of FVIIa and FIXa inhibitors are reported which are successful during in-silico designing, in-vitro, in-vivo assays, but only few of them get promising outcomes in pre-clinical and clinical trials. Some of them have been stopped during clinical trials. Table 1 contain class of drugs that are successful in clinical trials. Some of them have been stopped due to negative results in clinical trial.

\section{SUMMARY}

Current therapy of anticoagulants have several limitations, including enhanced chance of bleeding, variable patient response and narrow clinical applications. As inhibition of FVIIa and FIXa lead to blockage of both intrinsic and extrinsic pathways of coagulation, these two factors play a fundamental role in coagulation cascade, which are activated by TF or contact initiated activation. Even though major efforts and some success was achieved in discovery of potent synthetic inhibitors of FVIIa/ TF and FIXa, no compounds have been advanced into clinical trials. FIX inhibitors constantly show effective anticoagulation and reduced risk of bleeding. The only orally available FIXa inhibitor TTP889 has undergone clinical trials (Phase I and Phase II) and it was well tolerated in humans. But it is recommended that only partial inhibition was not an effective drug design strategy for the prophylaxis of VTE in patients with hip fracture surgery. Due to negative results in FIXIT study development of TTP889 was stopped. Development of orally available anticoagulant with complimentary reversible antidote is the major challenge in the drug design and development. After warfarin only RNA aptamers (Pegnivacogin) was developed with reversible antidote anivamersen. RNA aptamer with antidote anivamersen can produce effective coagulation and quick reversal in clinical trial Phase I study and in animal models. Clinical trials of RNA aptamer are currently in progress and Phase III trials have been started which will provide safety and pharmacokinetic profile and the required information will be beneficial for the development of novel drug. Even though such complexity is observed in designing of anticoagulant as FVIIa/TF complex and FIXa inhibitors, these will remain a significant and validated target for the development of the next generation anticoagulants.

\section{CONCLUSION}

As anticoagulants are used as preventive agents to prevent blood clots. They have some limitations. FVIIa and FIXa are the important targets in designing of novel anticoagulants, due to their tactical presence at the junction of both extrinsic and intrinsic pathways. This review is expected to serve the needs of Pharmaceutical Sciences student in particular and also researchers of other related profession such as Medicine.

\section{ACKNOWLEDGMENTS}

The authors are thankful to UGC for funding Major Research Project MRP-MAJOR-PHAR-2013-39160 also thankful to Dr. H. N. More, Principal Bharati Vidyapeeth College of Pharmacy, Kolhapur (M. S.) India for providing facilities to carry out the research work.

\section{CONFLICTS OF INTEREST}

The authors declare no conflicts of interest.

\begin{tabular}{|c|c|c|c|c|c|}
\hline \multicolumn{7}{|c|}{ Table 1: Clinical trial status of FIXa inhibitors.52-54 } \\
\hline Class of Drug & $\begin{array}{c}\text { Mechanism of } \\
\text { Action }\end{array}$ & Pharmacokinetics & $\begin{array}{c}\text { Pharmacod- } \\
\text { ynamics }\end{array}$ & Antidote & $\begin{array}{c}\text { Clinical development } \\
\text { phase }\end{array}$ \\
\hline $\begin{array}{c}\text { Oral inhibitors } \\
\text { TTP889 }\end{array}$ & Still not available & $\begin{array}{c}\text { Data not } \\
\text { available }\end{array}$ & Numans & $\begin{array}{c}\text { Development has } \\
\text { been stopped }\end{array}$ \\
\hline $\begin{array}{c}\text { RNA aptamers } \\
\text { pegnivacogin }\end{array}$ & $\begin{array}{c}\text { Oligonucleotide binds } \\
\text { FIX/FIXa }\end{array}$ & $\begin{array}{c}\mathrm{t}_{1 / 2}=12 \text { hrs in primate } \\
\text { model }\end{array}$ & Dose dependent & $\begin{array}{c}\text { Reversible } \\
\text { antidote } \\
\text { Anivamersen }\end{array}$ & $\begin{array}{c}\text { Completed Phase I \& started Phase III trial } \\
\text { II }\end{array}$ \\
\hline $\begin{array}{c}\text { Active site-blocker } \\
\text { Inhibitors IXai }\end{array}$ & $\begin{array}{c}\text { Competitively block } \\
\text { active site }\end{array}$ & $\begin{array}{c}\mathrm{t}_{1 / 2}=90 \text { min in primate } \\
\text { model }\end{array}$ & Dose dependent & No & $\begin{array}{c}\text { Development has } \\
\text { been stopped }\end{array}$ \\
\hline $\begin{array}{c}\text { Monoclonal } \\
\text { antibodies } \\
\text { SB 249417 }\end{array}$ & $\begin{array}{c}\text { Murine antibody, } \\
\text { humanized } \\
\text { against GLA domain }\end{array}$ & $\begin{array}{c}\mathrm{t}_{1 / 2}=90 \mathrm{hrs} \text { in primate } \\
\text { model }\end{array}$ & $\begin{array}{c}\text { Dose dependent } \\
\text { Kd } 20 \text { nmol/L }\end{array}$ & No & $\begin{array}{c}\text { Development has } \\
\text { been stopped }\end{array}$ \\
\hline
\end{tabular}




\section{ABBREVIATION USED}

HIT: Heparin-induced thrombocytopenia; TF: Tissue Factor; VTE: Venous Thromboembolism; EGF: Epidermal Growth Factor.

\section{REFERENCES}

1. Rang HP, Dale MM, Ritter JM, Moore PK. Pharmacology. Churchill Livingstone $5^{\text {th }}$ ed. London, England; 2003. 314-25.

2. Brummel KE, Paradis SG, Butenas S, Mann KG. Thrombin functions during tissue factor-induced blood coagulation. Blood. 2002;100(1):148-52.

3. Golino P. The inhibitors of the tissue factor: factor VII pathway. Thromb Res. 2002;106: V257-65

4. Giesen PL, Rauch U, Bohrmann B, Kling D, Roque M, Fallon JT, et al. Bloodborne tissue factor: another view of thrombosis. Proc Natl Acad Sci U S A. 1999;96(5):2311-5.

5. Majerus PW, Miletich JP. Relationships between platelets and coagulation factors in hemostasis. Annu Rev Med. 1978;29(1):41-9.

6. Gerotziafas GT, Samama MM. Heterogeneity of synthetic factor Xa inhibitors. Curr Pharm Des. 2005;11(30):3855-76.

7. Bhatia MS, Ingale KB, Choudhari PB, Bhatia NM, Sawant RL. Application quantum and physico chemical molecular descriptors utilizing principal components to study mode of anticoagulant activity of pyridyl chromen-2-one derivatives. Bioorg Med Chem. 2009;17(4):1654-62.

8. Bohm M, Sturzebecher J, Klebe GJ. Three-Dimensional Quantitative Structure-Activity Relationship Analyses Using Comparative Molecular Field Analysis and Comparative Molecular Similarity Indices Analysis To Elucidate Selectivity Differences of Inhibitors Binding to Trypsin, Thrombin, and Factor Xa Med. Chem. 1999;42(3):458-77.

9. Weitz JI, Bates SM. New anticoagulants. J Thromb Haemost. 2005;3:1843-53.

10. Weitz $\mathrm{JI}$, Hudoba M, Massel D. Clot-bound thrombin is protected from inhibition by heparin-antithrombin III but is susceptible to inactivation by antithrombin III independent inhibitors. J Clin Invest. 1990;86(2):385.

11. Perez A, Eraso L, Merli G. Implications of new anticoagulants in primary practice. Int J Clin Pract. 2013;67(2):139-56

12. Vílchez JA, Gallego P, Lip Gregory YH. Safety of new oral anticoagulant drugs: a perspective. Ther Adv Drug Saf. 2014;5(1):8-20.

13. Lee WM, Larrey D, Olsson R, Lewis JH, Keisu M, Auclert L, et al. Hepatic findings in long-term clinical trials of ximelagatran. Drug Safety. 2005;28(4):351-70.

14. AstraZeneca, "AstraZeneca Decides to Withdraw Exanta" 2006; (Press release).

15. Hogg PJ, Jackson CM. Fibrin monomer protects thrombin from inactivation by heparin-antithrombin III: implications for heparin efficacy. Proc Natl Acad Sci U S A. 1989;86(10):3619-23.

16. Weitz JI, Hudoba M, Massel D, Maraganore J, Hirsh J. Clot-bound thrombin is protected from inhibition by heparin-antithrombin III but is susceptible to inactivation by antithrombin III-independent inhibitors. J Clin Invest. 1990;86(2):385-91.

17. De CR, Husted S, Wallentin L, Agnelli G, Bachman F, Baigent C, et al. Anticoagulants in heart disease: current status and perspectives. Eur Heart J. 2007;28:880-913.

18. Banner DW, D'Arcy A, Chene C, Winkler FK, Guha A, Konigsberg WH, et al. The crystal structure of the complex of blood coagulation factor VIla with soluble tissue factor. Nature. 1996;380:41-6.

19. Rebecca AS, George PV. Inhibitors of Factor VIla/Tissue Factor Arterioscler Thromb Vasc Biol. 2007;1895-8.

20. Choudhari PB, Bhatia MS. Development of N-Phenyl-3-Pyridin-2-YI Imino Derivatives As Anticoagulants Potential Factor VIla Inhibitors. J Chil Chem Soc. 2013;58, $N^{\circ}$ 2:1667-73.

21. Schweitzer BA, Neumann WL, Rahman HK, Kusturin CL, Sample KR, Poda GI. Structure-based design and synthesis of pyrazinones containing novel P1 'side pocket' moieties as inhibitors of TF/VIla. Bioorg Med Chem Lett. 2005;15:3006-11.
22. Kohrt JT, Filipski KJ, Cody WL, Cai C, Dudley DA, Van Huis CA. The discovery of fluoropyridine-based inhibitors of the factor VIla/TF complex. Bioorg Med Chem Lett. 2005;15:4752-6.

23. Vlife MDS: Molecular Design Suite 4.3. In., 3.0 edn; 2004: Vlife Sciences Technologies Pvt. Ltd., Pune, India

24. Protein database http://www.rcsb.org/pdb/home/home.do

25. Halgren TA. Molecular Geometries and Vibrational Frequencies for MMFF94. J Comput Chem. 1996;17(5-6):553-86.

26. Biggs R, Douglas AS, Macfarlane RG, Dacie JV, Pitney WR. "Christmas disease: a condition previously mistaken for haemophilia". British Medical Journal. 1952;2(4799):1378-82.

27. Zhong D, Bajaj MS, Schmidt AE, Bajaj SP. "The N-terminal epidermal growth factor-like domain in factor IX and factor $\mathrm{X}$ represents an important recognition motif for binding to tissue factor". The Journal of Biological Chemistry. 1952;277(5):3622-31.

28. Mathur A, Zhong D, Sabharwal AK, Smith KJ, Bajaj SP. Interaction of factor IXa with factor VIIla: effects of protease domain $\mathrm{Ca} 2$ _ binding site, proteolysis in the autolysis loop, phospholipid, and factor X. J Biol Chem. 1997;272(37):23418-26.

29. Zhong D, Smith KJ, Birktoft JJ, Bajaj SP. First epidermal growth factor-like domain of human blood coagulation factor IX is required for its activation by factor VIla/tissue factor but not by factor Xla. Proc Natl Acad Sci U S A 1994;91(9):3574-8.

30. Gudderra NP, Ribeiro JM, Andersen JF. Structural determinants of factor IX(a) binding in nitrophorin 2, a lipocalin inhibitor of the intrinsic coagulation pathway. J Biol Chem. 2005;280:25022-8.

31. Ananyeva NM, Kouiavskaia DV, Shima M, Saenko EL. Intrinsic pathway of blood coagulation contributes to thrombogenicity of atherosclerotic plaque. Blood. 2002;99:4475-85

32. Christopher RJ, Mark C, Emily LH, Becker KCD, Christopher PR, Becker RC. Factor IXa as a Target for Pharmacologic Inhibition in Acute Coronary Syndrome. Cardiovascular Therapeutics. 2011;29(4):e22-e35.

33. Schmaier AH, Dahl LD, Rozemuller AJ, Roos RA, Wagner SL, Chung R, et al. Protease nexin-2/ amyloid beta protein precursor. A tight-binding inhibitor of coagulation factor IXa. J Clin Invest. 1993;92(5):2540-5.

34. Samis JA, Kam E, Nesheim ME, Giles AR. Neutrophil elastase cleavage of human factor IX generates an activated factor IX-like product devoid of coagulant function. Blood. 1998;92(4):1287-96.

35. Hopfner KP, Lang A, Karcher A, Sichler K, Kopetzki E, Brandstetter H Coagulation factor IXa: the relaxed conformation of Tyr99 blocks substrate binding. Structure. 1999;7(8):989-96

36. Jakobsen $\mathrm{P}$, Pedersen BR, Persson E. Inhibitors of the tissue factor/ factor VIla-induced coagulation: synthesis and in vitro evaluation of novel specific 2-aryl substituted 4H-3,1-benzoxazin-4-ones. Bioorg Med Chem. 2000;8(8):2095-103

37. Riggs JR, Hu H, Kolesnikov A, Leahy EM, Wesson KE, Shrader WD, et al. Novel 5-azaindole factor VIla inhibitors. Bioorganic and Medicinal Chemistry Letters. 2006;16(12):3197-200.

38. Shrader WD, Kolesnikov A, Rai R, Hendrix J, Hu H, Torkelson S, et al. Factor VIla inhibitors: Gaining selectivity within the trypsin family. Bioorganic and Medicinal Chemistry Letters. 2006;16(16):1596-600

39. Young WB, Mordenti J, Torkelson S, Shrader WD, Kolesnikov A, Rai R, et al. Factor VIla inhibitors: Chemical optimization, preclinical pharmacokinetics, pharmacodynamics, and efficacy in an arterial baboon thrombosis model. Bioorganic and Medicinal Chemistry Letters. 2006;16(7):2037-41.

40. Parlow JJ, Kurumbail RG, Stegeman RA, Stevens AM, Stallings WC, South MS. Design, synthesis, and crystal structure of selective 2-pyridone tissue factor VIla inhibitors. J Med Chem. 2003;46(22):4696-701.

41. Hu H, Kolesnikov A, Riggs JR, Wesson KE, Stephens R, Leahy EM, et al. Potent 4-amino-5-azaindole factor VIla inhibitors. Bioorganic and Medicinal Chemistry Letters. 2006;16(17):4567-70.

42. Dange V, Sprengeler PA, Shaghafi M, Spencer JR, Katz BA, Yu C, et al. Discovery of novel hydroxy pyrazole based factor IXa inhibitor. Bioorganic and Medicinal Chemistry Letters. 2006;16(10):2796-9.

43. Parker Jr DL, Walsh S, Li B, Kim E, Sharipour A, Smith C, et al. Rapid development of two factor IXa inhibitors from hit to lead. Bioorg Med Chem Lett. 2015;1-5. 
44. Gao JS, Tong XP, Chang YQ, He YX, Mei YD, Tan PH, et al. Design and prediction of new anticoagulants as a selective Factor IXa inhibitor via three-dimensional quantitative structure-property relationships of amidinobenzothiophene derivatives. Drug Design, Development and Therapy. 2015;9:1743-59.

45. Wang S, Beck R, Burd A, Blench T, Marlin F, et al. Structure based drug design: development of potent and selective factor IXa (FIXa) inhibitors. $J$ Med Chem. 2010;53(4):1473-82.

46. Choudhari P, Bhatia M. 3d QSAR, Pharmacophore Identification Studies on Series of 4-Substituted Benzothiophene Analogs as Factor IXa Inhibitors. Pharmacophore 2012; 3 Suppl 3: 189-198.

47. Eriksson $\mathrm{BI}$, Dahl OE, Lassen MR, Ward DP, Rothlein R, Davis G, et al. Fixit Study Group. Partial factor IXa inhibition with TTP889 for prevention of venous thromboembolism: An exploratory study. J Thromb Haemost. 2008;6(3):457-63

48. Howard EL, Becker KCD, Rusconi CP, Becker RC. Factor IXa inhibitors as novel anticoagulants. Arterioscler Thromb Vasc Biol. 2007;27(4):722-7.
49. Ellington $A D$, Szostak JW. In vitro selection of RNA molecules that bind specific ligands. Nature. 1990;346(6287):818-22.

50. Weitz JI. New antithrombotic drugs: antithrombotic therapy and prevention of thrombosis, $9^{\text {th }}$ ed: American College of Chest Physicians Evidence- Based Clinical Practice Guidelines. Chest. 2012;141:120S-151S.

51. Dyke CK. First-in-human experience of an antidote-controlled anticoagulant using RNA aptamer technology: a Phase 1a pharmacodynamic evaluation of a drug-antidote pair for the controlled regulation of factor IXa activity. Circulation. 2006;114(23):2490-7.

52. Howard EL, Becker Kristian CD, Rusconi CP, Becker RC. Factor IXa Inhibitors as Novel Anticoagulants. Arterioscler Thromb Vasc Biol. 2007;27(4):722-7.

53. Smiley DA, Becker RC. Factor IXa as a target for anticoagulation in thrombotic disorders and conditions. Drug Disc Today 2014; 19( suppl 9): 1445-1453.

54. Benedict CR, Ryan J, Wolitzky B, Ramos R, Gerlach M, Tijburg P, et al. Active site-blocked factor IXa prevents intravascular thrombus formation in the coronary vasculature without inhibiting extra vascular coagulation in a canine thrombosis model. J Clin Invest. 1991;88(5):1760-5.

\section{Pictorial Abstract}

FACTOR VIII AND FACTOR IXa INHIBITORS AS ANTICOAGULANTS: A REVIEW
S. S. KUMBHAR*, P. B. CHOUDHARI, V. S. PAWAR, N. M. BHATIA, M. S. BHATIA

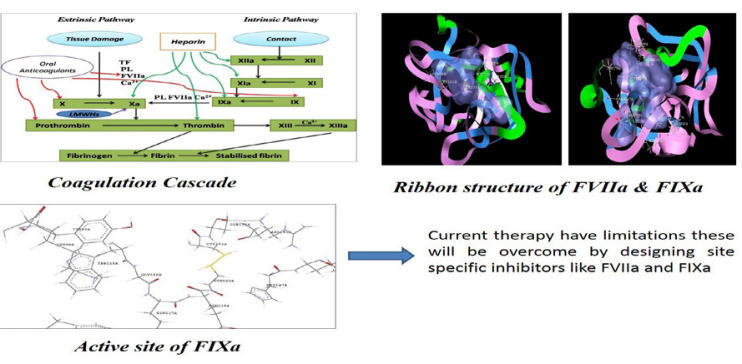

\section{About Authors}

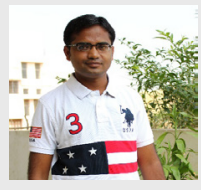

Mr. Santosh S. Kumbhar M. Pharm. Project Fellow UGC Major Research Project at Bharati Vidyapeeth College of Pharmacy, Kolhapur (MS). He has 10 international publications with cumulative Impact Factor 3.7 to his credit. Also published one book in Lambert Academic Publishing. His area of Interest is in Drug Design and Development.

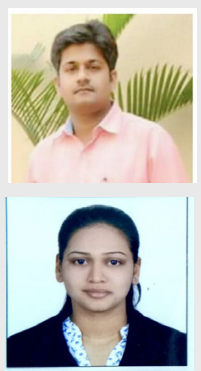

Dr. Prafulla B. Choudhari M. Pharm., Ph.D. Assist. Professor at Bharati Vidyapeeth College of Pharmacy, Kolhapur (MS). He has $>70$ international and national publications with cumulative Impact Factor $>30$ to his credit. He has guided $4 \mathrm{M}$. Pharm. research projects.

Mrs. Vasanti S. Pawar M. Pharm. II Research student at Bharati Vidyapeeth College of Pharmacy, Kolhapur (MS). She is actively research in the area of Nutraceuticals.

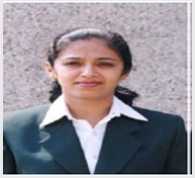

Dr. Mrs. Neela M. Bhatia M. Pharm., Ph.D. Professor and HOD Dept. of Quality Assurance at Bharati Vidyapeeth College of Pharmacy, Kolhapur (MS). She has 3 applied patent, 73 international and national publications to her credit. She has guided $>45 \mathrm{M}$. Pharm. and $08 \mathrm{Ph}$.D. research projects.

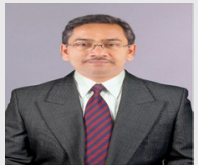

Dr. Manish S. Bhatia M. Pharm., Ph.D. Professor and Vice-Principal at Bharati Vidyapeeth College of Pharmacy, Kolhapur (MS). He has 08 applied patent, 121 international and 25 national publications with Cumulative Impact Factor $>54$ to his credit. He also published 03 books. He has guided 56 M. Pharm. and $17 \mathrm{Ph} . \mathrm{D}$. research projects.

Cite this article: Sahadeo KS, Balkrishna CP, Suresh PV, Manish BN, Sudesh BM. Factor VIla and Factor IXa Inhibitors as Anticoagulants: A Review. Indian Journal of Pharmaceutical Education and Research. 2017;51(1):1-8. 